\title{
Indicadores de constitucionalidad de las políticas públicas: enfoque de gestión de derechos ${ }^{1}$
}

Constitutionality indicators of public policies: approach of rights management

Angélica María Rodríguez Cely ${ }^{2}$

Fecha de recepción: 6 de junio de 2014

Fecha de aprobación: 4 de octubre de 2014

\section{RESUMEN}

En este texto se presenta la línea jurisprudencial consolidada de la Corte Constitucional acerca de la constitucionalidad de las políticas públicas orientadas a garantizar un derecho constitucional mediante la cual se han precisado unos requisitos que deben satisfacer las políticas públicas para ser constitucionales, estos requisitos operan como indicadores de constitucionalidad de las políticas públicas.

Palabras clave: política pública, sentencia estructural, Jjudicialización de la política, gestión de derechos, indicadores de constitucionalidad.

1 El artículo es producto del proyecto de investigación "Indicadores de constitucionalidad de las políticas públicas", el cual fue gestionado en la Universidad Nacional de Colombia, para optar al título de Magister en Derechos Humanos y Democratización.

2 Magister en Derechos humanos y democratización - Universidad Nacional de Colombia. Correo Electrónico: am.rodriguez.ce@gmail.com 


\section{Abstract}

In this text the jurisprudential line established by the Colombian Constitutional Court on the constitutionality of public policies to guarantee a constitutional right by which they have specified some requirements to be met by public policy to be constitutional, presents these requirements operate as indicators constitutionality of public policy.

Keywords: Public policy, judgment structural, judicialization of politics, rights management, indicators of constitutionality.

\section{INTRODUCCIÓN}

Este artículo se propone responder a la cuestión de si ¿A través de los fallos estructurales la Corte Constitucional ha creado unos criterios de validez-racionalidad constitucional de las políticas públicas que podrían denominarse como enfoque de gestión de derechos? La hipótesis del texto es que efectivamente a través de la jurisprudencia (no solo de los fallos estructurales) de la Corte Constitucional se ha modificado en Colombia el enfoque de las políticas públicas, el cual es un hibrido entre el enfoque de gestión y el enfoque de derechos, cuya máxima expresión son los indicadores de constitucionalidad de las políticas públicas orientadas a garantizar un derecho constitucional.

Con el propósito de demostrar esta hipótesis, en la primera parte se aborda el lugar de las decisiones judiciales en el ciclo de las políticas públicas a través de lo que se ha denominado judicialización de la política, y se responde a la cuestión de si está justificada la intervención judicial en las políticas públicas.

Para efectos de este texto, se entiende por política pública el "conjunto de acciones planeadas, ejecutadas y evaluadas por actores públicos y privados que, a partir de la lectura, la sistematización y el análisis de las demandas sociales, estructuran conceptual, operativa y financieramente un conjunto de planes, programas y proyectos que tienen por finalidad mitigar, y en ocasiones erradicar, los problemas 
a los que la sociedades confiere el estatus de problema de interés general”. (Pérez, 2007)

Esta definición contiene los cuatro elementos señalados por Roth como característicos de una política pública, a saber "1) la identificación de situaciones en las cuales se pretende intervenir, bien sea porque se trata de eventos considerados como problemáticos, o bien porque existen intereses políticos que exigen que así se haga; 2 ) la definición de objetivos que guiarán la intervención en las situaciones previamente identificadas; 3) la creación y el diseño de programas, acciones o medidas que tengan como propósito la consecución de los objetivos trazados con anterioridad, y 4) todo ello, contando con la participación del Estado, bien sea esta directa o indirecta." (citado por Quinche \& Rivera, 2010).

Adicionalmente se debe considerar que, las políticas públicas están compuestas de varias etapas, denominadas "ciclo de las políticas públicas", que comprenden: 1) la definición del problema, esto es la ubicación en la agenda pública de una problemática socialmente relevante, 2) la formulación o el diseño luego de un proceso de estudio

3 Este autor llega a esta definición a partir de considerar las siguientes definiciones antecedente:

“...(...)programa de acción gubernamental llevado a cabo por autoridades investidas de legitimidad pública en un sector de la sociedad o en un espacio geográfico concreto. Dicho trabajo abarca múltiples aspectos, que van desde la definición y selección de prioridades de intervención hasta la toma de decisiones, su administración y evaluación. (Mény y Thoening, 1992, p. 90)

Las politicas públicas son un factor común de la politica y de las decisiones del Gobierno y de la oposición. La politica puede ser analizada como la búsqueda de establecer politicas públicas sobre determinados asuntos, o de buscar influir en ellos. A su vez, parte fundamental del quehacer del Gobierno se refiere al diseño, gestión y evaluación de las politicas públicas. Entre los objetivos de los políticos se encuentra el de establecer políticas públicas que impulsen sus compromisos politicos o bloquear aquellas que resulten contrarias a sus objetivos. (Lahera, 2004, p. 7)

Una politica pública es un conjunto de sucesivas iniciativas, decisiones y acciones del régimen politico frente a situaciones socialmente problemáticas y que buscan la resolución de las mismas o llevarlas a niveles manejables. La política pública es la concreción del Estado en acción, en movimiento frente a la sociedad y sus problemas. (Vargas, 1999, p. 57)

Desde la óptica monopolizadora del Estado, "las politicas públicas corresponden a las acciones decididas, levadas a cabo y autorizadas por el Estado, representado por el Gobierno, de cara a proteger o promover un bien considerado como de interés público" (Roth, 2006, p. 60). "(Pérez Murcia, 2007) 
y discusión, de una serie de medidas por medio de las cuales se pretende solucionar determinado problema (planes, programas y proyectos); 3) la implementación concreta de las medidas formuladas, y 4) la evaluación o seguimiento de las medidas adoptadas y de los efectos que ha producido su implementación. (Quinche $\&$ Rivera, 2010)

A partir de este marco conceptual, en la segunda parte se abordan los estudios antecedentes respecto del problema planteado y se responde a la cuestión de si ¿Existe una transformación de las políticas públicas en Colombia a partir de la intervención de la Corte Constitucional mediante fallos estructurales?. Así a partir de la reseña de tres estudios que abordaron los impactos de la Sentencia T-025 de 2004 se demuestra la efectiva transformación en los ciclos de las políticas públicas a partir de la intervención de la Corte Constitucional.

En la tercera parte del texto, se responde a la cuestión de si existe una línea jurisprudencial acerca de la constitucionalidad de las políticas públicas orientadas a garantizar un derecho constitucional, y se describen sus características. Así se abordan las cuestiones no exploradas por los estudios antecedentes y se demuestra la existencia de unos indicadores de constitucionalidad de las políticas públicas que determinan su validez.

A partir de esta descripción se evidencia la existencia de un nuevo enfoque -hibrido- denominado enfoque de gestión de derechos, a partir del cual nuestra Corte Constitucional determina la validez constitucional de las políticas sociales.

Este nuevo enfoque y la existencia de los indicadores de constitucionalidad de las políticas sociales impactan positivamente el proceso de democratización del Estado Colombia y constituyen un avance importante para el logro de los fines que como sociedad organizada hemos definido en nuestra Constitución Política, entre ellos la vigencia de los derechos humanos y la existencia de un orden social justo, dado que se constituye en una herramienta para el análisis, evaluación y exigibilidad de los derechos que se pretenden garantizar y proteger a través de las políticas orientadas a garantizar un derecho constitucional. 


\section{LA JUDICIALIZACIÓN DE LA POLÍTICA PÚBLICA}

En este apartado se pretende responder a la cuestión de si está justificada la intervención del Juez Constitucional en las políticas públicas. Esta cuestión se aborda a partir del neoconstitucionalismo, entendido como modelo institucional de organización política $^{4}$. En Colombia, el neoconstitucionalismo como ideología ha sido de amplia aceptación por nuestra Corte Constitucional ${ }^{5}$ y por un amplio sector de la doctrina jurídica nacional ${ }^{6}$.

Colombia se ha caracterizado como un Estado Constitucional de Derecho, heredero del proceso de democratización de la tercera ola de transiciones a la democracia 7 . Nuestra Constitución no solo establece la estructura de la organización política, las competencias y los procedimientos sino que además incluye un amplio catálogo de normas que condicionan la actuación del Estado por medio del establecimiento de fines y objetivos de la organización política.

La Constitución Política de 1991 se encuentra en la cúspide de nuestro ordenamiento jurídico, de la adecuación a su contenido se deriva la validez de todas las normas

4 De acuerdo con (Prieto, 2007) el neoconstitucionalismo puede entenderse como Modelo institucional, Teoría del Derecho que explica ese modelo institucional o ideología que justifica ese modelo institucional.

5 Sobre este punto Garcia Jaramillo destaca el importantísimo papel de la Corte Constitucional en la implantación de las tesis neoconstitucionalistas y señala que la "Corte Constitucional es vanguardia en el constitucionalismo de la región. la importancia del rol de la Corte Constitucional en 20 años de creación y desarrollo del derecho. Ha visibilizado muchos problemas sociales que antes sólo eran conocidos por especialistas que los estudiaban, permitiendo así que adquirieran significancia política. Ha forzado a sectores importantes de la política y la opinión pública a prestarle atención a cuestiones sociales antes ignoradas, así como a configurar una postura frente a ellas. Institucionalizó el Estado Social de Derecho que, como modelo ideológico y formula política, cuenta con elementos básicos como el respeto a la dignidad humana (art. 1), la proclamación de principios de democracia, participación y pluralismo (art. 1), la atribución a la Constitución de carácter supremo (art. 4), la primacía de los derechos inalienables de la persona (art. 5), el reconocimiento de un amplio catálogo de derechos fundamentales y sociales (tit. 2, caps. 1 y 2) y la garantía jurisdiccional de la Constitución (cap. 4). en (Garcia, 2011).

6 En este sentido ver: (Uprimny, 2007); (Upimny \& Rodríguez, 2007) (Cepeda, 2004) (Quinche \& Rivera, 2010).

7 "En lo que respecta a América Latina, este cambio se debió, en parte, a la ola de transiciones a la democracia que experimentaron muchos países de la región a partir de la década de 1980. Este proceso no fue un fenómeno autóctono sino parte de uno más amplio que afectó también a otras regiones del mundo (Huntington, 1996; Linz y Stepan, 1996)" citado en (Herrero, 2011). 
de inferior jerarquía y de las actuaciones de las autoridades. La Constitución es el horizonte y límite de la actuación de las autoridades públicas y de los ciudadanos.

La Constitución Colombiana de 1991 es una "Constitución normativa garantizada" (Prieto Sanchis, 2007), esto es, que "genera de modo directo derechos y obligaciones de aplicación directa e inmediata, que pueden hacerse valer a través de los procedimientos jurisdiccionales existentes para la protección de derechos, principalmente a través del Juez Constitucional”. (Prieto, 2007).

Rodrigo Uprimny avanza en esta caracterización y señala que "la Constitución colombiana de 1991 es una constitución normativa y valorativa de constitucionalismo social", esto es, que "no solo reconoce derechos liberales, sino también derechos sociales y les otorga fuerza normativa" (Uprimny \& Rodríguez, 2007:36); Adicionalmente, señala que la Constitución colombiana de 1991 es una constitución abierta $^{8}$, lo cual implica que las políticas públicas sociales y económicas están limitadas constitucionalmente?

Que la Constitución colombiana sea una constitución normativa, valorativa de constitucionalismo social, abierta y garantizada, significa que los objetivos y fines en ella establecidos pueden reclamarse directamente ante el juez constitucional. En este contexto el rol de la Corte Constitucional es un rol protagónico ${ }^{10}$, dado que

8 "La tesis que defendemos es la siguiente: la Constitución colombiana es i) vinculante como norma jurídica, en cuanto establece límites legales a la acción de los poderes públicos, y ii) valorativa porque consagra principios y valores específicos. Sin embargo, sostenemos que la Constitución es también abierta, porque no constitucionaliza un modelo económico preciso sino que admite políticas económicas y sociales diversas, aunque dentro de ciertos límites normativos y valorativos.” (Upimny \& Rodríguez, 2007).

9 "Es difícil encontrar hoy en día una Constitución totalmente abierta o plenamente neutra frente a la política económica, porque en la medida en que el ordenamiento superior tenga fuerza normativa y reconozca derechos constitucionales, impone límites a la política económica. Por ello, es indudable que ciertas políticas económicas o sociales son inconstitucionales. Sin embargo, esto no significa que la Constitución institucionalice un modelo económico determinado y excluya la posibilidad de que existan múltiples alternativas de desarrollo dentro del marco fijado por los derechos constitucionales. La Constitución de un Estado social, fundado en los derechos sociales, debe ser entonces abierta, pero no neutra, sin que eso acabe el pluralismo y socave la legitimidad del ordenamiento jurídico”. (Upimny \& Rodríguez, 2007:35)

10 El protagonismo judicial se explica por algunos autores en las condiciones históricas de la democratización de la tercera ola así: "En dicho contexto, los especialistas en teoría democrática iniciaron una aproximación gradual a los poderes judiciales ya que éstos enfrentaban importantes desafíos directamente asociados con la 
es garante de la realización de la Constitución, y de la garantía y protección de los derechos en ella reconocidos, en las decisiones del legislativo y el ejecutivo ${ }^{11}$. La función del juez Constitucional en un Estado Social de Derecho es asegurar el goce efectivo, no teórico, de los derechos fundamentales ${ }^{12}$.

En Colombia el mayor número de decisiones de la Corte Constitucional es provocado por los ciudadanos que reclaman por la violación de sus derechos fundamentales por parte de la autoridad obligada a garantizarlos, en estos casos, la reclamación de derechos por parte de los ciudadanos es la que activa la intervención del juez constitucional en la revisión de las actuaciones de las autoridades. Ver al respecto la gráfica No. 1 .

Como resultado de la revisión de estas solicitudes de Tutela, la Corte Constitucional se ha visto avocada a analizar políticas públicas concretas y ha identificado problemas estructurales en ellas que les impiden garantizar los derechos reconocidos en la Constitución. Estos análisis estructurales se asemejan teóricamente a la figura del litigio estructural desarrollada en Estados Unidos. (Bugallo, 2013).

De acuerdo con Bugallo el litigio de reforma estructural se caracteriza por: "1. La multiplicidad de actores e intereses en juego; 2 . El carácter estructural de la violación

consolidación de los nuevos regímenes, tales como juzgar las violaciones a los derechos humanos por parte de los gobiernos militares; contribuir a la vigencia del estado de derecho y la Constitución; investigar escándalos de corrupción; y someter al mandato de la ley a estructuras estatales acostumbradas a funcionar bajo esquemas autoritarios. Si bien en la década de 1980 ya existía un sólido cuerpo de literatura sobre autoritarismo y quiebres democráticos (Schmitter y O’Donnell, 1986; O’Donnell et al., 1986 y 1988; Diamond, Linz y Lipset; 1990), el inusitado protagonismo de las cortes en las nuevas transiciones democráticas dio lugar a una nueva etapa de investigación y producción literaria. Uno de los temas que generó mayor interés fue la capacidad de los poderes judiciales de la región de actuar en estos procesos de manera independiente y controlar a los otros poderes del Estado (Stotzky, 1993; Nino, 1997; Schedler et al. , 1999; Przeworski et al., 1999; Teitel, 2002; Malamud Goti, 1996)” (Herrero, 2011).

11 "El control jurisdiccional de la función administrativa, es en suma, una consecuencia trascendental de la aplicación del principio de legalidad a la administración, pues supone que la misma está sujeta al bloque de legalidad, al derecho, los que se constituyen en parámetros permanentes de la actuación administrativa, fuera de cuyos márgenes deviene en irregular. El ámbito administrativo es permeado por el derecho, con lo que no quedan espacios exentos de su cobertura" (Lobo, 1997).

$12 \mathrm{Al}$ respecto ver apartado 8. De la Sentencia T-025 de 2004 de la Corte Constitucional. 
bajo análisis; 3. La necesidad de diseño de un remedio que requiere planificación e implementación de largo alcance; 4. La necesidad de respeto de la división de poderes, al ser, por lo general, la demandada una autoridad estatal.” [26] (Bugallo, 2013). (Rodríguez \& Rodríguez, 2010). Este tipo de litigio contribuye a armonizar las actuaciones de las autoridades públicas con los contenidos constitucionales, en especial, con el reconocimiento y efectividad de los derechos establecidos en la Constitución.

Gráfica 1. Decisiones proferida por la Corte Constitucional 1992-2014

$$
\text { "Sentencias de Tutela "Sentencias de Constitucionalidad " Autos }
$$

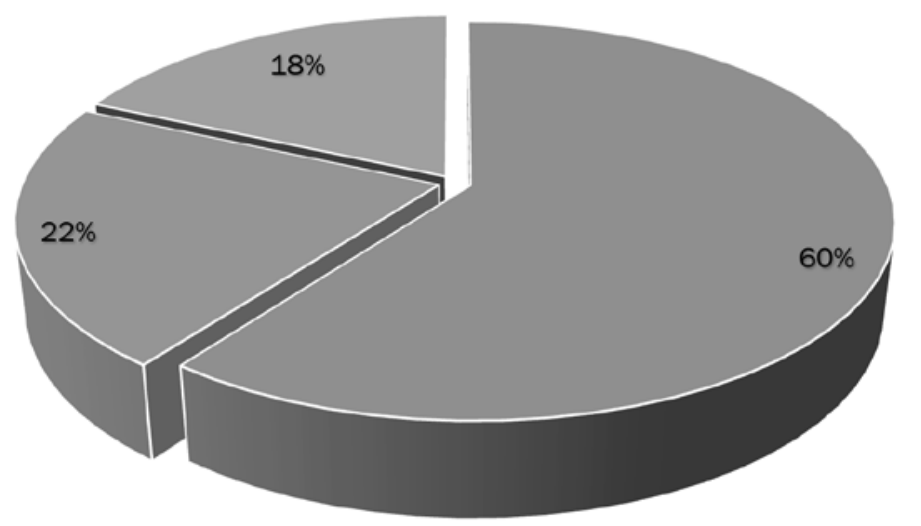

Fuente: estadística de la Corte Constitucional: consultada el 4 de marzo de 2014. http://www.corteconstitucional. gov.co/relatoria/estadisticas1992-2014.png . Número total de decisiones: 26320.

La figura del litigio estructural ha servido desde los años sesenta en los Estados Unidos para corregir las deficiencias o inequidades que conlleva la aplicación de prácticas o políticas públicas que no solamente resultaban inconsistentes con los derechos tutelados en la Constitución, sino que implicaban una violación sistemática de derechos civiles, políticos y sociales que profundizaban las 
desigualdades de carácter racial, de género, entre otras, en los Estados Unidos durante esa época (Olaiz \& Bosco, 2011).

En Colombia como consecuencia del litigo estructural, la Corte Constitucional en ejercicio de su rol de guardiana y garante de la Constitución la Corte, ha realizado un control judicial de las decisiones de política pública. Este control judicial de las políticas públicas se inserta en lo que se ha denominado judicialización de la política, entendida como, el condicionamiento judicial o la decisión judicial "sobre asuntos que tradicionalmente habían sido decididos por medios políticos, y que se consideraba que eran propios de la política democrática” (Uprimny, 2007).

En nuestra tradición jurídica la política pública se entendió como un conjunto de normas definidas por el legislativo, cuyo contenido eran obligaciones generales de alcanzar objetivos políticamente deseables de la organización estatal. En otros casos la política pública se trató como un asunto técnico de administradores públicos y economistas, definido exclusivamente por el ejecutivo. Con la judicialización de la política pública se hace evidente que tanto el legislativo como el ejecutivo están obligados a desarrollar los fines constitucionales en el ciclo de la política pública.

A la judicialización de la política se le han atribuido virtudes, tales como: (i) evitar abusos de los órganos políticos y de las mayorías, en contra de minorías estigmatizadas o de individuos (ii) situar en el centro del debate la protección de derechos; (iii) evidenciar que la garantía de los derechos más que limitación a la democracia es precondición de la misma. (Uprimny, 2007) ${ }^{13}$. Otros autores han destacado que la judicialización de la política es además "una herramienta útil para exigir que las políticas públicas cumplan con los compromisos que imponen los derechos humanos". (Quinche \& Rivera, 2010)

13 A este respecto se afirma "si los derechos fundamentales son tanto presupuestos procesales como materiales de la democracia, es obvio que estos derechos deben ser garantizados, independientemente de la opinión de las mayorías" (Uprimny, 2007:65). 
Uno de los efectos de la judicialización de la política es la juridización del discurso ${ }^{14}$ de las políticas públicas, esto implica que buena parte de la discusión se de en términos de derechos y obligaciones, con lo cual el debate de las políticas públicas se desconcentra de los discursos de la administración pública y de la economía.

En Colombia como resultado del Litigo estructural y de la judicialización de la política se han generado fallos estructurales de la Corte Constitucional en los cuales se ha evidenciado que los obstáculos para la garantía de los derechos humanos reconocidos por la Constitución están en la propia institucionalidad, en el proceso de diseño, implementación y evaluación de la política pública, razón que justifica la intervención de la Corte en el ciclo de la política pública con el fin de ajustar los procesos institucionales a las finalidades constitucionales de garantía y protección de los derechos humanos.

\section{IMPACTO EN LAS POLÍTICAS PÚBLICAS DE LOS FALLOS ESTRUCTURALES DE LA CORTE CONSTITUCIONAL}

El propósito de este apartado es responder a la cuestión de si ¿Existe una transformación de las políticas públicas en Colombia a partir de la intervención de la Corte Constitucional a través de fallos estructurales?, la tesis es que efectivamente hay una transformación de las políticas públicas a partir de las intervenciones de la Corte mediante fallos estructurales, situación que se ha evidenciado en otros estudios que se reseñan a continuación.

Los estudios reseñados en este apartado demuestran como la Corte Constitucional ha impactado cada una de las etapas del "ciclo de las políticas públicas" y ha generado transformaciones específicas en ellas a través de fallos estructurales ${ }^{15}$.

14 "Dicho judicialización ha generado que muchos actores sociales empiecen a formular sus demandas en términos jurídicos y judiciales" (Uprimny, 2007).

15 Los fallos estructurales son los que mayor impacto tienen en la política pública por la complejidad de sus órdenes y el número de actores involucrados, no obstante, como se demostrara más adelante, mediante sentencias de constitucionalidad, tutela y autos de seguimiento se ha consolidado la doctrina de la admisibilidad constitucional de las políticas públicas orientadas a garantizar un derecho constitucional. 
"Las sentencias de reforma estructural" como también se les denomina, se han definido como "aquellas decisiones por medio de las cuales se pretende mudar determinada organización burocrática para armonizarla con los mandatos de la Constitución" (Quinche \& Rivera, 2010:123).

Estos "casos estructurales"16 se han caracterizado por: "1) afectar un número amplio de personas que alegan la violación de sus derechos, ya sea directamente o a través de organizaciones que litigan su causa, 2) involucrar varias entidades estatales como demandadas por ser responsables de fallas sistemáticas de políticas públicas, y 3) implicar órdenes de ejecución compleja, mediante las cuales el juez de la causa instruye a varias entidades públicas a emprender acciones coordinadas para proteger a toda la población afectada (no solamente los demandantes del caso concreto)" (Rodríguez \& Rodríguez, 2010).

El fallo estructural hito en Colombia es la sentencia T-025 de 2004 ${ }^{17}$, cuyo ponente fue el Magistrado Manuel José Cepeda Espinosa, mediante la cual se declara "la existencia de un estado de cosas inconstitucional en la situación de la población desplazada debido a la falta de concordancia entre la gravedad de la afectación de los derechos reconocidos constitucionalmente y desarrollados por la ley, de un lado, y el volumen de recursos efectivamente destinado a asegurar el goce efectivo de tales derechos y la capacidad institucional para implementar los correspondientes mandatos constitucionales y legales, de otro lado". (Corte Constitucional, 2004).

16 "El objeto distintivo del litigio de reforma estructural es la eliminación o modificación de condiciones estructurales que dan lugar a una determinada situación de hecho - compleja, producto de distintas decisiones de múltiples agencias- que resulta violatoria de derechos." (Basch, 2010).

17 Otros autores han destacado la importancia de esta sentencia así: "En Colombia, la Corte Constitucional ha estado en la vanguardia de Latinoamérica en esta forma de encausar las soluciones a situaciones estructurales de violación de derechos, a las que denominó "estado de cosas inconstitucional”73. El tribunal colombiano ha echado mano de la figura del estado de cosas inconstitucional en casos de reforma de prisiones, y tal vez la decisión más gravitante en este sentido ha sido la sentencia T025/04, relativa a la situación de la población desplazada interna como resultado del conflicto armado, que ascendía a más de tres millones de personas. En este último caso, la Corte Constitucional no ordenó medidas precisas a ser cumplidas por el Estado, sino que convocó a éste junto con los demandantes y organizaciones de la sociedad civil a consensuar programas que dieran remedio a la crisis humanitaria existente. Esta forma de intervención dirigida a permitir la participación y la búsqueda de soluciones dialogadas fue complementada por una intensa actividad de monitoreo de los avances." (Basch, 2010). 
Este fallo se caracteriza como un fallo estructural por reunir las condiciones arriba descritas.

El primer estudio antecedente a reseñar es el texto de Leonardo García Jaramillo "Aproximación a la discusión sobre políticas públicas y justicia constitucional: a propósito del estado de cosas inconstitucional". En este texto el autor destaca la sentencia T-025 de 2004 y la doctrina del estado de cosas inconstitucional ${ }^{18}$ como modelo de solución judicial a la tensión existente entre "las particularidades del contexto social en el cual deben aplicarse las provisiones constitucionales" y las normas constitucionales; como fórmula para reducir la disociación entre derecho y realidad.

Este autor parte de considerar la existencia de una profunda contradicción entre una constitución ampliamente garantista como la colombiana y el contexto injusto y desigual en el cual debe aplicarse ${ }^{19}$, y concluye que estas características políticas y sociales de Colombia justifican la intervención de la Corte Constitucional en el proceso de formación de las políticas públicas, y sitúan a la doctrina del estado de cosas inconstitucional como un mecanismo para la transformación de la idea de constitución formal por constitución material.

Destaca el autor, que las causas por las cuales se presenta el estado de cosas inconstitucional están relacionadas "con problemas estructurales en las políticas públicas que consisten en acciones u omisiones estatales en el diseño, implementación y seguimiento de las

$18 \mathrm{El}$ autor concluye que "La doctrina del estado de cosas inconstitucional puede constituirse en un aporte del constitucionalismo colombiano a los procesos de aplicación del derecho en contextos marcados por la injusticia, la desigualdad y el déficit crónico en la protección de derechos" (Garcia, 2011).

19 "Colombia tiene un particularmente débil sistema de partidos que entre otros aspectos se refleja en una incapacidad de asumir tareas básicas. Dentro de sus factores sociales más elocuentes se encuentran la desigualdad, el desempleo, el subdesarrollo, las millones de personas víctimas del desplazamiento forzado por la violencia, la pobreza en la mitad de su población y la pobreza extrema en un alto grado; altos índices de criminalidad, impunidad y corrupción; y donde en general se violan los derechos humanos (por acción estatal, inacción o acción insuficiente) de forma tal que hay pocos parangones en el mundo. A pesar de mayor inversión extranjera y moderado crecimiento en la economía, hay más pobres que antes y cada día más personas tienen dificultades para satisfacer sus necesidades básicas mínimas. Se ha agudizado la brecha de la separación social pues cada vez hay más pobres, mientras que un pequeño grupo se beneficia de los modestos grados de progreso. Según cifras oficiales, Colombia es el cuarto país más desigual del mundo tratándose de distribución del ingreso." (Garcia, 2011:87). 
mismas, como consecuencia de lo cual sistemática y prolongadamente se han omitido diversos tipos de garantías o se han vulnerado de manera directa y generalizada los derechos fundamentales de un número plural de personas que hacen parte de poblaciones desfavorecidas y vulnerables”. (Garcia, 2011).

Sobre la sentencia T 025 de 2004 el autor señala que además de consolidar la doctrina del estado de cosas inconstitucional, "se trata de una sentencia particularmente importante porque no sólo definirá las directrices para la reparación a las víctimas del desplazamiento, sino en general a todas las víctimas del conflicto armado colombiano, por lo que quizá se podrá tomar como modelo para la reparación a las víctimas” (Garcia, 2011). El autor concluye que con este fallo la Corte se inserta en las tres etapas del ciclo de la política pública: i) la protección de un derecho social en un caso concreto mediante ordenes específicas de garantía (visibilización del problema), ii) la orden del diseño de un programa de atención integral (diseño de la política)) y iii) en el proceso de seguimiento a las anteriores órdenes (evaluación) ${ }^{20}$.

Estas conclusiones se mantienen en el segundo estudio reseñado sobre los efectos de la sentencia T-025 de 2004 titulado "Corte Constitucional colombiana: un actor relevante en el ciclo de las políticas. El caso de la política pública para la población desplazada por la violencia”, escrito por César Valderrama. En este estudio se llega a la conclusión principal de que la Corte Constitucional es un actor relevante en el estudio de las políticas públicas ${ }^{21}$.

20 "En concreto, tres etapas se pueden identificar en el rol que ha asumido la Corte respecto de la política concreta. Interviene protegiendo un derecho social en un caso concreto mediante una orden específica de garantía a ese derecho. Imparte otra orden para que se diseñe un programa de atención integral, luego como se dijo atrás de confrontar la realidad con un juicio de naturaleza constitucional. Además de impartir órdenes estructurales con remedios, establece unos plazos. En el diseńo del remedio en el cual articula los dos tipos de intervenciones anteriores, agrega una serie de órdenes encaminadas a dinamizar procesos y a establecer paramentos sustantivos para evaluar los resultados de esos procesos, lo cual es acompañado con un seguimiento para evaluar si las órdenes impartidas fueron cumplidas o no, y en qué grado." (Garcia, 2011).

$21 \mathrm{El}$ autor parte de considerar que "la falta de interés de los estudios en políticas públicas por este actor en particular, y el poco uso que le ha dado a los desarrollos metodológicos y conceptuales que se han hecho en la ciencia política, ha creado un vacío frente a la relevancia que tienen los jueces y cortes en el ciclo de las políticas públicas, la forma en que intervienen y los efectos que tiene sus decisiones en cada una de las etapas." (Valderrama Gomez, 2010). 
El objetivo de este texto fue "evidenciar cual fue el cambio general que la Corte le dio a la política, dónde fue más contundente, cuáles fueron los mecanismos jurídicos que usó para intervenir y de esta forma demostrar que la Corte Constitucional colombiana es un actor relevante en el ciclo de la política pública de desplazamiento" (Valderrama, 2010).

El estudio se propuso demostrar los efectos de la sentencia en dos momentos: (i) la definición del problema y (ii) la formulación o diseño de la política (restringido a funciones y actores); concluyendo que efectivamente a través de la sentencia la Corte redefinió el problema del desplazamiento forzado ya que se ampliaron los derechos, y se modificó parte del diseño ya que se ampliaron las facultades de la política "al aumentar las funciones de algunas autoridades que implementan y diseñan esta política pública e incorporar mecanismos de evaluación de la misma”. (Valderrama, 2010).

Valderrama destaca como uno de los efectos principales de la sentencia T-025 de 2004, haber cambiado el enfoque de la política pública de atención al desplazamiento forzado, así se afirma que "su diseño original propuesto por el poder legislativo y que reguló el ejecutivo era de beneficios más que de derechos, siendo ese precisamente el mayor cambio general que recibió con su judicialización: convertirse en una política con enfoque de derechos, no sólo desde el punto de su exigibilidad judicial, (...) sino frente a todas las características que este enfoque tiene: progresividad de los derechos, protección integral, garantía e inclusión de principios amplios y generales que desarrollan derechos humanos. (Valderrama, 2010).

Destaca así mismo el papel del proceso de seguimiento originado con la sentencia T-025 de 2004, así: "El papel de este tipo de decisiones, ha sido fundamental como un intento de la Corte para evitar que sus decisiones sean letra muerta que nadie acate y olvide, dinamizando las acciones de los obligados a actuar y manteniendo un diálogo constante con todas las partes que integran la política pública" (Valderrama, 2010); y lo caracteriza como una buena práctica judicial, "definiendo aspectos generales, modulando el efecto temporal de sus decisiones para permitir que las instituciones pertinentes tomen los correctivos necesarios, estableciendo mínimos en derechos a partir de los cuales las políticas públicas 
deben ser desarrolladas, sirviendo como canal de comunicación de sectores sociales excluidos, entre otros”. (Valderrama, 2010).

Uno de los estudios más completos de los efectos de las sentencia T-025 de 2004, es el elaborado por César Rodríguez Garavito y Diana Rodríguez Franco, titulado "Cortes y cambio social. Cómo la Corte transformó el desplazamiento forzado en Colombia”.

A partir de las tesis constructivistas, los autores destacan los efectos simbólicos de la sentencia ${ }^{22}$, tales como: "la aparición del problema del desplazamiento en la agenda pública, la movilización social a favor de los derechos de los desplazados, el cambio de la percepción de la urgencia y gravedad del desplazamiento en la opinión pública, y la transformación gradual del aparato estatal que atiende a la población desplazada, entre otros". (Rodriguez \& Rodriguez, 2010)

El estudio se enmarca en la discusión sobre la naturaleza, la legitimidad y la utilidad de la intervención de los jueces en la solución de problemas sociales estructurales, como los que están en juego en los casos sobre derechos sociales. Destacan que desde la sentencia T-025 se encuadro la discusión en el diálogo conceptual entre política pública y derechos humanos, partiendo de evidenciar las fallas estructurales de la política pública antes de la intervención de la Corte.

Este estudio caracteriza a la sentencia T-025 de 2004, además de ser un fallo estructural, de ser un fallo representativo del activismo dialógico caracterizado por (i) dictar órdenes abiertas; (ii) prever su implementación mediante mecanismos de seguimiento periódicos y públicos; e (iii) involucrar otros actores en el proceso de seguimiento ${ }^{23}$.

22 César Rodríguez (2014) en su marco teórico describe como los estudios sociojurídicos se han centrado en responder de un lado (neorrealistas) a la pregunta por los efectos directos de los fallos judiciales, es decir, la constatación de una cambio en la conducta de sus destinatarios inmediatos, y de otro (constructivistas), a la pregunta por los efectos indirectos o simbólicos de estos mismos fallos. Su estudio se enmarca en la segunda corriente y demuestra los efectos simbólicos de la sentencia T-025 de 2004.

23 "Los fallos representativos del activismo dialógico comparten tres rasgos. Primero, las sentencias dialógicas tienden a dictar órdenes más abiertas que las del activismo clásico. En términos de los criterios de Tushnet (2008) para distinguir los remedios judiciales "fuertes" de los "débiles" — esto es, la amplitud, la obligatoriedad y la perentoriedad de las órdenes del fallo_-, sus remedios tienden a ser más débiles. Las sentencias de la jurisprudencia 
De acuerdo con la elaboración conceptual del texto se identifican seis efectos principales de la sentencia T-025 de 2004, así: i) Efecto desbloqueador ${ }^{24}$, ii) Efecto deliberativo ${ }^{25}$, iii) Efector creador $^{26}$, iv) Efecto coordinador $^{27}$, v) Efecto social ${ }^{28}$ y el Efecto de políticas públicas, si bien en el texto no se define que se entiende por este efecto, dado que al abordar los anteriores efectos se alude al concepto de política pública de modo permanente, no obstante, los autores al analizar este efecto resaltan que "uno de los aspectos más significativos del fallo y los autos es que su aparato

dialógica tienden a abrir un proceso de seguimiento que alienta la discusión de alternativas de políticas públicas para solucionar el problema estructural detectado en el fallo. Los detalles de las políticas, por tanto, tienden a surgir en el transcurso del proceso de seguimiento, no en la sentencia misma. Con frecuencia, además, las órdenes de los fallos no implican obligaciones de resultado muy precisas, sino el deber de las autoridades públicas de diseñar e implementar políticas que avancen en la protección de los derechos vulnerados." (Rodriguez \& Rodriguez, 2010:55).

24 Este se define por los autores como la posibilidad de la sentencia de producir acciones por parte del aparato estatal respecto de un problema específico sobre el que había cierta "inercia”. Este efecto en el caso particular se explica así: "las reacciones inmediatas del Estado a la T-025 muestran que la sentencia remeció, por lo menos parcialmente, la inercia institucional en temas como el presupuesto dedicado a la atención a los desplazados, la reactivación del inoperante sistema de coordinación interinstitucional, y la expedición de algunos programas de emergencia”, se señala que adicionalmente en su primera fase "Se trató de un caso clásico de reenvío del problema el Ejecutivo, en el que el poder judicial busca desbloquear el proceso de políticas públicas sin arrogarse el poder de definir los detalles de éstas”. (Rodriguez \& Rodriguez, 2010).

25 Este efecto se define por los autores como la capacidad de la sentencia de propiciar espacios de deliberación de actores involucrados en un caso concreto. Sobre este efecto se señaló que "la T-025 amplió el abanico de actores, públicos y privados, que participan en el proceso de discusión de políticas públicas sobre el desplazamiento". Adicionalmente, se identificó como una consecuencia negativa de este efecto "la juridización del conflicto" los cual ha generado "que el proceso de seguimiento sea más accesible a los actores expertos en el leguaje del derecho y los derechos que a quienes resultan directamente afectados por los mismos”.

26 Este efecto es definido como la posibilidad de crear nuevas dimensiones o formas de abordar el problema por parte de las sentencias estructurales, así se afirma que con la Sentencia T-025, "la Corte contribuyó a enmarcar la situación de los desplazados — que antes era considerada un efecto colateral del conflicto armado— como un problema de violación de derechos humanos que requería una reacción inmediata. Así, i) el caso contribuyó a hacer visible el tema, ii) lo enmarcó como un problema de derechos humanos y iii) creo un campo sociojurídico del desplazamiento con actores, procedimientos y formas de intervención".

27 Este efecto se define como la posibilidad del fallo de servir de regulador y organizador de las interacciones entre los distiontos actores de la política pública. "la Corte ha terminado jugando un rol racionalizador de la política pública al promover este tipo de coordinación, tanto entre las entidades directamente involucradas por el fallo como entre las entidades indirectamente relacionadas con el caso". En este aspecto se reconoce que si bien la Sentencia provoco la generación de nuevos espacios de coordinación y diálogo, persisten algunos límites en la articulación y comunicación interinstitucional.

28 Este efecto se pregunta por el impacto que ha tenido la sentencia sobre la población final. Sobre este punto se determinó que persisten las situaciones que generaron el estado de cosas inconstitucional. 
conceptual y su lenguaje son un híbrido ${ }^{29}$ entre: 1) las herramientas jurídicas del derecho constitucional y el derecho de los derechos humanos, y 2) las herramientas de la economía y las políticas públicas". Según los autores, "Esta combinación tuvo un efecto de políticas públicas directo y tangible" que "modificó la manera como se diseñaban políticas públicas", ello se evidencia en la inclusión del "enfoque de derechos", el "enfoque diferencial”, los "elementos mínimos de racionalidad del programa en tanto componente de una política pública” y los requisitos mínimos que deben cumplir los programas y proyectos piloto.

Se destaca como la muestra más clara de este efecto el diseño de los indicadores de goce efectivo de derechos, ya que "marcaron un giro en la lógica de medición de las políticas, que pasaron a ser evaluadas en términos de la satisfacción de derechos humanos", siendo el paradigma del "híbrido jurídico-económico del efecto de políticas públicas".

En los tres estudios reseńados se dejan en evidencia los impactos de la Sentencia t-025 en cada una de las etapas del ciclo de la política pública de atención al desplazamiento forzado, los cuales pueden sintetizarse así:

Por otra parte, en el texto de Manuel Fernando Quinche y Juan Camilo Rivera, titulado "El control judicial de las políticas públicas como instrumento de inclusión de los derechos humanos", se aborda el estudio de otro fallo estructural que evidencia las transformaciones en la política pública a través de las intervenciones de la Corte Constitucional.

En este texto se parte de considerar que los derechos humanos establecen los objetivos que deben guiar las políticas públicas, no obstante no siempre son

29 "De las primeras proviene la lógica legal y prescriptiva que lleva a la Corte a concluir la existencia de una violación masiva de derechos y declarar el estado de cosas inconstitucional. De las segundas vienen la lógica organizacional y los instrumentos de análisis y medición de políticas con los que la Corte diagnostica las fallas estructurales de la administración pública e impulsa el diseño, la ejecución y la evaluación de nuevas políticas, que incluye un largo y sofisticado proceso de construcción de indicadores de avance o retroceso en la garantía de los derechos de los desplazados. El caso no ha consistido, entonces, en la imposición de la lógica jurídica sobre la económicoadministrativa, sino en una combinación de ambas”. (Rodriguez \& Rodriguez, 2010:55). 
tenidos en cuenta por quienes las elaboran o ejecutan, "En este contexto, el control judicial puede ser una herramienta útil para exigir que en el proceso de formulación, implementación y evaluación de políticas públicas se tomen en cuenta las obligaciones que se desprenden de los derechos humanos", el texto demuestra que a través de los fallos de reforma estructural se pueden transformar las políticas públicas que desconocen los derechos humanos y promover la inclusión de estos derechos en el ciclo de la política pública.

Tabla 1. Síntesis de efectos de la sentencia t-025

evidenciados en los estudios antecedente

\section{DEFINICIÓN DEL PROBLEMA}

- Inlcusión del enfoque de derechos y obligaciones

- Revitalización de la Constitución

\section{DISEÑO DE LA POLÍTICA}

- Inclusión de la participación de destinatarios en el diseño

- Parametros mínimos que deben reunir los planes, programas y proyectos

\section{IMPLEMENTACIÓN}

- Inclusión de la participación de destinatarios en la ejecución

- Redefinición de competencias institucionales

- Generación de espacios de diálogo interinstitucional

- Énfasis en la información

\section{EVALUACIÓN}

- Generación de espacios de diálogo interinstitucional con la participación de destinatarios de la política, sociedad civil, entes de control y comunidad internacional en el proceso de seguimiento y evaluación.

- Fortalecimiento de los procesos de rendición de cuentas

- Medición de los resultados de la política a través de indicadores de goce efectivo de derechos. 
A partir del análisis de la importancia de las normas jurídicas constitucionales para las políticas públicas y para el cumplimiento de las obligaciones de respeto y garantía del Estado derivadas de la existencia de los derechos humanos, se llega a la conclusión de que:

las políticas públicas y los derechos humanos son temas y contenidos mutuamente implicados, ya que los derechos humanos establecen límites, márgenes y obligaciones para las políticas públicas. Adicionalmente, las obligaciones derivadas de los derechos implican que las políticas públicas se erijan en el medio idóneo para su realización, ayudando a traducir entidades con algún grado de abstracción (las normas sobre derechos humanos) en prestaciones concretas (la entrega de medicamentos, subsidios para vivienda, etc. (Quinche \& Rivera, 2010:120).

Posteriormente en el texto se evidencia que en contextos como el colombiano donde no se llega a la realización de los derechos humanos a través de las iniciativas de políticas públicas diseñadas por el legislador y el ejecutivo, la intervención del juez constitucional en la revisión de las políticas públicas resulta la única forma de lograr el cumplimiento de los derechos humanos reconocidos en la Constitución. Intervención que se realiza, entre otras, mediante sentencias de reforma estructural.

El texto reseñado analiza la Sentencia T-760 de 2008, de la cual también es ponente el Magistrado Manuel José Cepeda Espinosa y en la cual se acumulan 22 procesos de tutela en los cuales se solicita la protección del derecho a la salud y se emiten órdenes de carácter general que van más allá de los casos analizados ${ }^{30}$. Los autores del texto reseñado, seleccionan esta sentencia, dado que en ella se emitieron órdenes generales relacionadas con aspectos estructurales de la política pública de salud y se mantuvo la práctica de supervisión al cumplimiento de las órdenes generales impartidas. Esta sentencia se muestra como una forma de control judicial fuerte ya que establece objetivos, los objetivos son medibles, y se establecen plazos específicos de cumplimiento. (Quinche \& Rivera, 2010).

30 Queda pendiente analizar los motivos que llevaron a la Corte a no declarar el estado de cosas inconstitucional en este caso, pues siguiendo la doctrina del estado de cosas inconstitucional fijada por la misma Corte, se reunían los elementos para su declaración. 
De acuerdo con los autores en la Sentencia T760 de 2008, se evidenciaron fallas estructurales de la política pública de salud, razón por la cual se ordenó la reformulación de la política, el diseño de un programa de implementación y el establecimiento de un mecanismo de supervisión de la sentencia.

Posteriormente el texto analiza las discusiones generadas con este tipo de fallos, y destaca como efecto positivo de este tipo de pronunciamientos, el aumento del control social de las políticas públicas a través de la participación de la sociedad civil en el proceso de seguimiento al cumplimiento de las órdenes del fallo, con lo cual, se refuerzan las conclusiones de los estudios anteriores respecto de la efectiva transformación del ciclo de evaluación de las políticas públicas a partir de los fallos estructurales de la Corte Constitucional.

Como se observa, los estudios reseñados se concentran en justificar la intervención de la Corte en la política pública a través de los fallos estructurales, a partir de la identificación de los efectos positivos que genera, tales como i) la visibilización de problemas de respeto y garantía de los derechos humanos; ii) la democratización del ciclo de la política pública mediante la participación; y iii) el fortalecimiento de los procesos de evaluación de las políticas públicas.

Los autores coinciden en señalar como efecto principal de la intervención de la Corte la inclusión del enfoque de derechos en las políticas públicas. Rodríguez Garavito \& Rodríguez Franco (2010) destacan sobre este punto el esfuerzo de la Corte por compatibilizar el marco conceptual de derechos con el marco conceptual de la política pública y señalan como la máxima expresión de este esfuerzo la exigencia de los indicadores de goce efectivo de derechos.

No obstante lo anterior, en los estudios reseñados no se destaca la existencia de una línea jurisprudencial consolidada de la constitucionalidad de las políticas públicas sociales, que no se ha desarrollado exclusivamente a través de los fallos estructurales, mediante la cual se han establecido unos mínimos de racionalidad que condicionan la validez constitucional de las políticas públicas, tema que será abordado en el próximo apartado. 


\section{INDICADORES DE CONSTITUCIONALIDAD DE LAS POLÍTICAS PÚBLICAS ORIENTADAS A GARANTIZAR UN DERECHO CONSTITUCIONAL: EL ENFOQUE DE GESTIÓN DE DERECHOS}

Una vez evidenciados los impactos y transformaciones en las políticas públicas mediante los fallos estructurales de la Corte Constitucional, se debe responder varias cuestiones, a saber: ¿Existe una línea jurisprudencial consolidada de la constitucionalidad de las políticas públicas orientadas a garantizar un derecho constitucional? ¿Existen unos indicadores de constitucionalidad de las políticas públicas orientadas a garantizar un derecho constitucional? ¿Existe un nuevo enfoque teórico de análisis de las políticas públicas?

A partirdel análisis delaSentencia T-025de 2004, se identifica unalínea jurisprudencial consolidada de la constitucionalidad de las políticas públicas orientadas a garantizar un derecho constitucional, según la cual el diseño y ejecución de las mismas está sujeto a unos criterios constitucionales de obligatorio cumplimiento.

El hito fundacional de esta línea se encuentra en la sentencia T-595 de 2002 en la cual se fijan tres condiciones de constitucionalidad de las políticas públicas orientadas a garantizar un derecho constitucional, a saber:

1. La política pública debe estar plasmada en un plan, ello implica que no basta con el reconocimiento de un derecho o de una obligación a través de una ley, decreto u otra norma, es necesaria la existencia de un plan que haga efectiva su realización.

"Se desconoce entonces la dimensión positiva de un derecho fundamental en sus implicaciones programáticas, cuando ni siquiera se cuenta con un plan que conduzca, gradual pero seria y sostenidamente a garantizarlo y protegerlo." ${ }^{31}$

2. El plan debe estar encaminado a garantizar el goce efectivo del derecho, ello implica que las obligaciones del Estado no se agotan con el reconocimiento

31 Corte Constitucional, Sentencia T-595 de 2002, MP: Manuel José Cepeda Espinosa. 
formal de la existencia de un derecho sino que se requiere de acciones que conduzcan a su realización efectiva. De este criterio la Corte deriva dos situaciones de inconstitucionalidad: i) la existencia de un plan o programa que solo esté escrito y no haya iniciado su ejecución; ii) que si el plan se está ejecutando, éste no responda a los verdaderos problemas y necesidades de los titulares del derecho en cuestión.

3. El plan debe ser sensible a la participación ciudadana, esto es debe permitir la participación de los directamente afectados en su diseño, ejecución y evaluación. De este criterio la Corte deriva dos situaciones de inconstitucionalidad: "que exista un plan que (i) no abra espacios de participación para las diferentes etapas del plan, o (ii) que sí brinde espacios, pero éstos sean inocuos y sólo prevean una participación intrascendente". (Corte Constitucional, 2002).

En la sentencia T595 de 2002, la Corte señala que el tiempo opera como criterio de evaluación del cumplimiento de los mandatos constitucionales en materia de políticas públicas, así:
"A medida que pasan los ańos, si las autoridades encargadas no han tomado medidas efectivas que aseguren avances en la realización de las prestaciones protegidas por los derechos constitucionales, gradualmente van incurriendo en un incumplimiento cuya gravedad aumenta con el paso del tiempo". (Corte Constitucional, 2002).

Este aspecto es de especial relevancia si se tiene en cuenta que, si bien existe un mandato de realización progresiva de los derechos, el cual fue esgrimido sistemáticamente por el estado para justificar la inactividad en materia de protección y garantía de derechos de contenido prestacional, con el paso del tiempo se hace mayor la exigencia inmediata al estado de una actuación destinada a garantizar estos derechos.

Estos contenidos mínimos constitucionales a seguir por las políticas públicas respecto de la garantía de un derecho fundamental, cuando son necesarias acciones progresivas por parte del Estado han sido reiterados en diez oportunidades por la Corte Constitucional en las sentencias T-792 de 2005, T-133 de 2006, T-884 de 

2012, C351 de 2013 y T-442 de 2013.

De lo anterior podemos concluir que existe una línea jurisprudencial consolidada de la constitucionalidad de las políticas públicas orientadas a garantizar un derecho constitucional, que incluye la definición de tres condiciones de constitucionalidad y que ha tenido efectos materiales en casos concretos en los cuales se ha realizado i) la exigencia del diseño de políticas públicas; ii) la exigencia de elaboración de planes concretos; iii) la exigencia de progresividad; iv) la inclusión de la participación en todo el ciclo de la política pública.

Ahora corresponde determinar si existen, a partir de esa línea jurisprudencial, unos indicadores de constitucionalidad de las políticas públicas. En este texto se entenderá por indicador de constitucionalidad de la política pública una condición verificable a partir de la cual se llega a una conclusión respecto de la adecuación de una política pública a los mandatos constitucionales. Aquí no se usaran los indicadores como instrumento de medida, ya que la constitucionalidad no admite grados.

Para responder a la cuestión planteada se parte de la sentencia T-025 de 2004, en la cual se reitera esta línea jurisprudencial de la constitucionalidad de las políticas públicas orientadas a garantizar un derecho y se avanza en su desarrollo, esto por cuanto: i) se condiciona la constitucionalidad de una política pública a partir del desarrollo del concepto de Estado Social de Derecho y los deberes constitucionales de las autoridades frente a la dimensión prestacional de los derechos, precisando las implicaciones del mandato de progresividad; ii) se sistematiza la doctrina del estado de cosas inconstitucional ${ }^{32}$ y se establece como consecuencia de la inconstitucionalidad

32 "La Corte ha declarado un estado de cosas inconstitucional en los siguientes asuntos: (1) omisión en la inclusión de docentes cotizantes al fondo prestacional del magisterio, (2) violación de derechos de sindicados y reclusos (salud, seguridad social y por hacinamiento), (3) falta de protección a la vida de los defensores de derechos humanos, (4) ineficiencia administrativa en la Caja Nacional de Previsión (Cajanal) para el trámite de pensiones de jubilación y mora reiterada en resolver derechos de petición, (5) dilación injustificada en la liquidación y pago de pensiones (Gobernación de Bolívar T-525 de 1999 y Gobernación de Chocó SU-090 de 2000), (6) desplazamiento y (7) omisión de convocatoria a concurso público para la carrera notarial." (Garcia, 2011). Para un análisis de la evolución de la línea jurisprudencial del estado de cosas inconstitucional, entre otros, ver: (Gómez, 2010). 
de una política pública y iii) a partir de un juicio de coherencia entre fines y medios, se identifican los medios (acciones u omisiones de las autoridades públicas) constitucionalmente inadmisibles para el desarrollo de las políticas públicas con las que se pretenden garantizar y proteger derechos de carácter prestacional.

A continuación se detallan los apartes de la sentencia T-025 de 2004 en los que se observan las anteriores características. En primer lugar la Corte establece que se está en presencia de un estado de cosas inconstitucional cuando:

“(...) se constata la vulneración repetida y constante de derechos fundamentales, que afectan a multitud de personas, y cuya solución requiere la intervención de distintas entidades para atender problemas de orden estructural $(\ldots)^{33}$ (2004)

La Corte reseńa las decisiones anteriores en las cuales se ha constatado la existencia de un estado de cosas inconstitucional, y caracteriza sus dos razones fundamentales así.

(..) se está ante un estado de cosas inconstitucional cuando "(1) se presenta una repetida violación de derechos fundamentales de muchas personas - que pueden entonces recurrir a la acción de tutela para obtener la defensa de sus derechos y colmar así los despachos judiciales - y (2) cuando la causa de esa vulneración no es imputable únicamente a la autoridad demandada, sino que reposa en factores estructurales."

Después de analizar las implicaciones normativas del Estado Social de Derecho la Corte subraya la existencia de una relación inescindible entre las políticas públicas y la realización de los derechos de contenido prestacional, siendo las primeras un medio y las segundas un fin imperativo y perentorio. Directamente la Corte deriva dos clases de deberes para el Estado así:

33 Ver entre otras, las sentencias T-068 de 1998, MP: Alejandro Martínez Caballero; T-153 de 1998, MP: Eduardo Cifuentes Muñoz; SU-250 de 1998, MP: Alejandro Martínez Caballero; T-590 de 1998, MP: Alejandro Martínez Caballero; T-606 de 1998, MP: José Gregorio Hernández Galindo; SU-090 de 2000, MP: Eduardo Cifuentes Muńoz; T-847 de 2000, MP: Carlos Gaviria Díaz; T-1695 de 2000, MP: Marta Victoria Sáchica Méndez. 
Por una parte, debe adoptar e implementar las políticas, programas o medidas positivas para lograr una igualdad real de condiciones y oportunidades entre los asociados y al hacerlo, dar cumplimiento a sus obligaciones constitucionales de satisfacción progresiva de los derechos económicos, sociales y culturales básicos de la población en aplicación de lo que la jurisprudencia constitucional ha denominado "cláusula de erradicación de las injusticias presentes" 34 . Y, por otra, debe abstenerse de adelantar, promover o ejecutar políticas, programas o medidas ostensiblemente regresivos en materia de derechos económicos, sociales y culturales, que conduzcan clara y directamente a agravar la situación de injusticia, de exclusión o de marginación que se pretende corregir, sin que ello impida avanzar gradual y progresivamente hacia el pleno goce de tales derechos $^{35}$. (Corte Constitucional, 2002).

Como se lee, el Estado tiene por un lado un deber de diseñar y ejecutar políticas públicas que garanticen los derechos constitucionales y por el otro, tiene el deber de hacer que esas políticas públicas que se ejecuten contribuyan efectivamente a la garantía del derecho en cuestión.

El primer deber implica que i) el estado no puede ser indiferente a situaciones de marginalidad y exclusión, por lo que en primera instancia debe identificar estas situaciones como problemáticas constitucionalmente relevantes y diseñar políticas públicas destinadas a la garantía de los derechos afectados por ellas; ii) la realización de los derechos de carácter prestacional requiere que el Estado incorpore en sus políticas, programas y planes, recursos y medidas encaminadas a avanzar de manera gradual en el logro de las metas que el propio Estado se haya fijado; iii) el estado puede fijar los medios y los tiempos de implementación de los mismos, esta decisión

34 Corte Constitucional, Sentencia SU-225 de 1997, MP: Eduardo Cifuentes Muñoz, donde la Corte ordena a las autoridades estatales adoptar todas las medidas necesarias para garantizar la vacunación gratuita para prevenir meningitis a niños pertenecientes a sectores históricamente marginados, con base en la cláusula de erradicación de las injusticias presentes. Esta jurisprudencia ha sido reiterada entre otras, en las sentencias T-177 de 1999, MP: Carlos Gaviria Díaz; T-840 de 1999, MP: Eduardo Cifuentes Muñoz, T-772 de 2003, MP: Manuel José Cepeda Espinosa.

35 Ver, en este sentido, la sentencia C-671 de 2002 (M.P. Eduardo Montealegre Lynett). (Corte Constitucional, 2002). 
debe estar sustentada "en un proceso decisorio racional que estructure una política pública susceptible de ser implementada”; y iv) el diseño y la implementación de estas políticas puede ser exigida por vía judicial.

Frente al segundo deber, en la T-025 de 2004, la Corte constató que los obstáculos para la garantía de los derechos humanos reconocidos por la Constitución a las víctimas de desplazamiento forzado estaban en la propia institucionalidad, en el proceso de diseño, implementación y evaluación de la política pública. Al evaluar la política pública de atención al desplazamiento forzado, la Corte encontró que si bien en su diseño legal se ajustaba a los estándares internacionales y se preveía atención por cada una de las etapas del desplazamiento, la implementación de este diseño estaba seriamente afectado por dos problemas principales: precariedad de la capacidad institucional ${ }^{36} \mathrm{y}$ asignación insuficiente de recursos. Al respecto la Corte precisa:

"Los problemas de la capacidad institucional se presentan en (i) el diseńo y el desarrollo reglamentario de la política pública dirigida a responder al desplazamiento forzado; (ii) la implementación de la política, y (iii), el seguimiento y la evaluación de la gestión realizada en la ejecución de la política. La respuesta del Estado sufre graves deficiencias en cuanto a su capacidad institucional, que abarcan todos los niveles y componentes de la política, y por lo tanto impiden de manera sistemática la protección integral de los derechos de la población desplazada". Por otra parte, "la insuficiencia de recursos se considera la causa central de las fallas en la implementación de políticas de atención a la población desplazada, es por ello que el nivel de ejecución de las políticas es insuficiente frente a las necesidades de la población desplazada y que los índices de cobertura de sus distintos componentes son tan bajos". (Corte Constitucional, 2004).

36 Los problemas de capacidad institucional son un denominador común de los casos estructurales. "En términos de sociología del Estado (Mann 1993: 60) se trata, entonces, de ausencia de "poder infraestructural” de las instituciones para implementar eficazmente una política pública y llegar a todo el territorio nacional. (Rodríguez \& Rodríguez, 2010:49). 
Estos problemas estructurales de la política pública de atención al desplazamiento forzado, irradian el análisis Constitucionalidad de la política pública y conducen a que en el proceso de seguimiento al cumplimiento de la sentencia T-025 de 2004, se avance en la definición de unos requisitos mínimos de racionalidad de las políticas públicas orientadas a garantizar un derecho constitucional.

La precisión de estos mínimos parte de considerar que "el goce efectivo de los derechos de fuerte contenido prestacional - como los derechos sociales- depende de que el Estado cree y mantenga las condiciones para dicho goce y adopte políticas encaminadas a su progresiva realización", así se establece una relación de medio a fin, entre la política pública y la garantía y protección de los derechos sociales; con lo cual estos mínimos se constituyen en un juicio de idoneidad de medios a fines.

Directamente en la sentencia T-025 se incluye como indicador cualitativo de constitucionalidad de las políticas públicas la coherencia. La coherencia apunta a que exista correlación entre lo que "promete" el Estado y los recursos económicos y la capacidad institucional para cumplir lo prometido.

La coherencia exige que si el Estado crea un derecho prestacional específico por vía de una ley, prevea que debe contar con los recursos para garantizar su goce efectivo y con la capacidad institucional para atender la demanda de servicios generada por la creación de ese derecho específico.

Este indicador cualitativo se complementa y se refuerza con el indicador de efectividad, el cual es transversal a todo el análisis efectuado por la Corte cuyo énfasis está en los resultados, en la garantía efectiva de los derechos en cuestión. Así por ejemplo en el auto se seguimiento a la sentencia T-025, el auto 219 de 2011, la Corte precisa que para evaluar la superación del estado de cosas inconstitucional no basta con la existencia de mejores leyes, nuevas instituciones o mayor inversión, sino que es necesario constatar su contribución efectiva al goce de derechos, así:

"Tal como ha sido señalado por la Corte Constitucional en varios autos de seguimiento, el criterio para declarar la superación del estado de cosas inconstitucional no es la realización de un esfuerzo presupuestal específico, 
el rediseño de políticas públicas, la expedición de nuevas y mejores leyes, la creación de macro estructuras administrativas, la entrega periódica de asistencia en especie o en dinero a las víctimas del desplazamiento, o el simple paso del tiempo, sino la garantía efectiva de los derechos de la población desplazada. En esa medida, dado que una de las razones para reconocer la existencia de un estado de cosas inconstitucional fue la vulneración generalizada y reiterada de los derechos de la población desplazada por la ausencia de políticas públicas idóneas, por la falta de capacidad institucional para atender adecuadamente a esta población y por la insuficiencia de los recursos asignados para la atención de este amplio grupo poblacional, corresponde a la Corte Constitucional verificar que las acciones adoptadas por el gobierno con la finalidad de atender la problemática del desplazamiento, conduzcan efectivamente al goce efectivo de los derechos de esta población.”

Esta orientación de la Corte Constitucional hacia los resultados ha permitido que se desarrolle una alta exigibilidad al gobierno de precisión en la definición de cómo lograr los objetivos de la política pública de desplazamiento. Así la Corte ha establecido requisitos específicos que deben contener las respuestas del gobierno a las exigencias de la Corte que vayan más allá de declaraciones programáticas de carácter general y que se traduzcan en acciones concretas a desarrollar.

Por ejemplo en el auto 219 de 2011, la Corte exige específica los marcos que debe contener el programa de prevención, así:

“(i) establezca un cronograma detallado de las acciones que pondrá en marcha para el diseńo y puesta en marcha del sistema nacional de derechos humanos en general y del componente de prevención en particular; (ii) precise las necesidades de capacidad institucional, coordinación interinstitucional y presupuestal requeridas para su efectiva implementación y sostenibilidad, la forma y el ritmo como serán atendidas y los ajustes que deberán realizarse y el tiempo previsto para su implementación; (iii) defina metas claras en materia de cobertura; (iv) desarrolle indicadores de goce efectivo de derechos para el componente de prevención del desplazamiento forzado; (iv) aclare la ruta para la articulación y armonización con el Sistema Nacional de Derechos Humanos 
y DIH, así como los funcionarios responsables; (v) esclarezca las competencias y responsabilidades en materia de prevención de las autoridades nacionales y territoriales y defina los mecanismos de coordinación; (vi) instituya los espacios y garantías de participación (...)

En los análisis de la Corte se evidencia un claro énfasis y preocupación por la implementación de las políticas públicas, lo anterior, por cuanto la Corte reconoce que en nuestra tradición jurídica e institucional, las leyes tienen un efecto declarativo y simbólico, más que un efecto práctico. En la sentencia C 873 de 2013, la Corte precisa que entiende por implementación así:

La "implementación" de una norma hace referencia al proceso por medio del cual la política que dicha norma articula jurídicamente es puesta en ejecución; se trata de una serie ordenada de pasos, tanto jurídicos como fácticos, predeterminados por la misma norma -o por aquellas que la desarrollen -, encaminados a lograr la materialización, en un determinado período de tiempo, de una política pública que la norma refleja. Por lo mismo, la noción de "implementación” tiene una dimensión jurídica, una dimensión material o fáctica y una dimensión temporal, cuyo contenido habrá de ser determinado por el Legislador. Analíticamente, una política pública primero es diseñada y luego es implementada ${ }^{37}$.

De acuerdo con lo anterior la implementación de la política pública tiene tres dimensiones que pueden ser evaluadas:

1. Una dimensión temporal, relativa al tiempo que tarda la puesta en marcha de la política diseñada. Con lo cual nuevamente se sitúa al tiempo como indicador cualitativo de constitucionalidad de la política pública. Así entre mayor tiempo pase entre el diseño y la implementación, más inconstitucional se vuelve la política.

37 En la práctica, el diseńo de la política pública puede incorporar elementos que anticipan el modo o el ritmo en que será implementada. Ver WILDAVSKY, Aaron: "Implementation". University of California Press, 1984. (WILDAVSKY, 1984) 
2. Una dimensión jurídica, relativa a la expedición de documentos de carácter normativo o vinculantes en los cuales se desarrollen las estrategias, lineamientos o finalidades establecidas en el documento que diseña la política pública.

En este punto es en el que más dificultades conceptuales existen. El tema de la delimitación conceptual entre política pública, plan, programa y proyecto es un debate abierto (Roth D, 2010). La Corte no ha contribuido a precisar estos conceptos, pues indistintamente se refiere a los planes y programas.

3. Una dimensión material o fáctica, relativa a la ejecución de acciones y actividades concretas que producen resultados verificables.

El énfasis en la implementación permea el concepto de política pública de la Corte Constitucional, especialmente en la dimensión material. Así se ve por ejemplo en la sentencia T 113 de 2009, en la que se precisa:

La política pública que ha formulado el Ejército Nacional en sus documentos oficiales es sensible a los derechos de los pueblos indígenas y es respetuosa de la Constitución Política vigente y del orden pluriéntico y multicultural que ella contempla. Pero una política pública no es el conjunto de promesas y de directrices que una autoridad pública formula en un texto. Una política pública la constituye el conjunto de acciones y omisiones de una autoridad sobre una cuestión. En tal sentido, la política del Ejército Nacional en materia de reclutamiento de poblaciones indígenas no la constituye un texto o un documento, sin importar cuál sea este, sino lo que en la realidad hace y deja de hacer la institución castrense a través de sus distintos miembros, en materia de reclutamiento de jóvenes indígenas.(Subraya fuera de texto).

De lo anterior podemos concluir que a partir de una clara preocupación por la materialidad de los derechos reconocidos en la constitución, la Corte ha enfatizado su actividad de judicialización de las políticas públicas en la verificación de la capacidad de las mismas para producir resultados concretos de satisfacción de derechos. Durante este proceso la Corte ha evidenciado la existencia de problemas de índole institucional, que la han conducido a precisar las condiciones o requisitos 
de las respuestas del Gobierno en materia de políticas públicas, especialmente ha precisado la segunda condición de constitucionalidad, esto es: la existencia de un plan. Así se han exigido los siguientes marcos mínimos que deben contener los planes o programas mediante los cuales se implemente una política pública:

(i) la elaboración y actualización periódica de un diagnóstico de la situación en que son ejercidos y disfrutados tales derechos por la población;

(ii) Racionalidad en el diseño, ejecución y articulación de las políticas públicas encaminadas a lograr progresivamente la realización plena de los derechos sociales las cuales han de incluir metas específicas para medir los avances en los plazos fijados: este criterio es el más desarrollado a través de los autos de seguimiento ${ }^{38}$, en ellos la Corte Constitucional ha desarrollado una doctrina consolidada acerca de los elementos mínimos de racionalidad que deben cumplir los programas diseñados como parte de una política pública orientadas a garantizar un derecho constitucional ${ }^{39}$, a saber:

- Derechos a garantizar mediante el programa y parámetros jurídicos de obligatorio cumplimiento. Ello incluye la Precisión de los mínimos de satisfacción del derecho en cuestión

- Especificidad individual del Programa.

- Definición de metas puntuales a corto, mediano y largo plazo

- Cronograma de implementación

- Cobertura material suficiente

38 Este proceso de evaluación y seguimiento ha hecho énfasis en cinco aspectos: (a) la adopción y aplicación de indicadores de goce efectivo de derechos; (b) la introducción de un enfoque diferencial en la respuesta estatal, principalmente respecto de las mujeres, los menores, los indígenas, los afrocolombianos y las personas con discapacidad; (c) la participación de las organizaciones de desplazados así como de la sociedad civil a través de la Comisión de Seguimiento dentro de una perspectiva a la vez crítica, propositiva y constructiva; (d) la rendición pública de cuentas de manera específica ante los propios desplazados por parte de los responsables de la implementación de los diferentes componentes de la política pública sobre desplazamiento forzado y (e) el compromiso de las entidades territoriales en la superación del estado de cosas inconstitucional. Auto 008 de 2009.

39 Estos mínimos han sido fijados por la Corte en la sentencia T-025 de 2004 y en los Autos 185 de 2004, 178 de 2005, 218 de 2006, 092 de 2008, 251 de 2008, 237 de 2008, 008 de 2009, 225 de 2009, 382 de 2012 y la sentencia T496 de 2008. 
- Presupuesto suficiente y oportunamente disponible: este criterio de suficiencia presupuestal señala que la realización de una política orientada a garantizar un derecho constitucional depende de la disponibilidad de recursos. Este criterio opera como indicador del avance o retroceso de la misma.

- Garantías de continuidad hacia el futuro

- Adopción e implementación de indicadores de resultado ${ }^{40}$, basados en el criterio del goce efectivo de los derechos fundamentales

- Diseño e implementación de mecanismos e instrumentos específicos de coordinación interinstitucional

- Desarrollo e implementación de mecanismos de evaluación y seguimiento

- Diseño e implementación de instrumentos de corrección oportuna

- Diseño e implementación de mecanismos internos de respuesta ágil y oportuna a las quejas o solicitudes puntuales de atención presentadas por la población desplazada.

- Diseño e implementación de mecanismos de divulgación periódica de información para la población beneficiaria. Sobre este punto la Corte ha precisado unos criterios mínimos ${ }^{41}$ de información detallada que deben garantizarse a los destinatarios de las políticas, a saber:

- Los bienes servicios a los que tiene derecho,

- Los momentos en los que éstos van a ser prestados

- Los responsables específicos de su prestación

- Los procedimientos y requisitos necesarios para su puntual prestación,

- Los remedios a los que tienen derecho si no se cumple lo prometido. Dentro de este componente, se habrá de

- procurar un medio centralizado de atención y orientación al que cualquier desplazado pueda tener acceso, tanto físicamente como a través de medios telefónicos o electrónicos, a la información descrita en este literal.

40 Los autos de seguimiento hacen énfasis "en el ajuste de los indicadores para medir el goce efectivo de los derechos de la población desplazada con el fin de evaluar la política pública, pues ésta carecía para ese momento de un sistema de evaluación que diera cuenta de su desempeńo y el logro de sus objetivos”. (Garcia, 2011).

41 Auto 008 de 2009. 
- adoptar y divulgar un protocolo para responder a las peticiones de servicios o prestaciones presentadas por integrantes de la población desplazada con el fin de que éstas reciban una respuesta que incluya la información en este literal.

- Armonización con los demás elementos de la política pública e integración formal a la misma

- Armonización con otros procesos y programas que se adelantan por el Gobierno Nacional o por otras autoridades

De lo anterior se concluye que efectivamente la Corte Constitucional en su línea jurisprudencial consolidada de la constitucionalidad de las políticas públicas orientadas a garantizar un derecho constitucional, ha construido una serie de indicadores de constitucionalidad de las políticas públicas, de cuyo análisis y verificación se concluye o no la adecuación de una política pública publica a los mandatos constitucionales.

Ahora corresponde determinar si a partir de la existencia de estos indicadores, se puede hablar de una modificación del enfoque de las políticas públicas. La tesis de este texto es que el énfasis de la Corte en la producción de resultados concretos y verificables, y en la precisión de los contenidos mínimos de los planes o programas mediante los cuales se pretende implementar una política pública podría denominarse como enfoque de "Gestión de Derechos" 42 , es decir, una combinación entre el enfoque de gestión ${ }^{43}$ y el enfoque de derechos ${ }^{44}$, cuyo objetivo es que todas las decisiones

42 Una conceptualización similar puede encontrarse en el enfoque operacional de los derechos humanos expuesto por Güendel (2000), según el cual la ética de los derechos se operativiza mediante las políticas públicas.

43 Por enfoque de gestión se entiende el proceso de toma de decisiones dentro de una organización, esto incluye el proceso de planificación, organización y gestión de los recursos destinados a lograr los resultados previstos, tanto mediante la optimización de la asignación de recursos como mediante el establecimiento de las funciones de los participantes. En resumen, el enfoque de gestión consiste en definir qué es lo que una organización quiere hacer y cuál es la mejor manera de hacerlo.

44 El enfoque de los derechos humanos pretende ser una nueva mirada que concibe los derechos humanos de manera integral, interdependiente y complementaria, superando de este modo, la visión tradicional de generaciones de derechos y la asimilación de los derechos fundamentales únicamente con los derechos humanos de primera generación. Otra característica de este enfoque es su preocupación por la concreción o materialización real de los derechos y la atención a grupos marginados. Dicha materialización se realiza mediante la adopción de políticas públicas con perspectiva de derechos y con amplia participación de la sociedad civil; de esta manera, los derechos humanos se convierten en el referente y fin último para las políticas públicas y éstas a su vez, en el instrumento o medio idóneo para su realización. De este modo, el enfoque de los derechos puede ser una perspectiva para guiar 
de política pública se encaminen a obtener como resultado el goce efectivo de los derechos.

Perez Murcia define la política pública con enfoque de derechos humanos como "aquella que se diseńa con fundamento en los contenidos de los derechos y que dispone de planes, programas, proyectos y recursos para implementar acciones concretas para dar cumplimiento a las obligaciones constitucionales e internacionales del Estado en la materia”. (Pérez 2007)

Esta política, según el autor tiene tres características principales:

1. Ser plenamente coherente con el respeto, protección y garantía de los derechos humanos asumidos conforme con los principios de universalidad, interdependencia y no discriminación;

2. Por formular estrategias técnicamente posibles de implementar;

3. Por ser factible y sostenible desde el punto de vista financiero.

El objetivo de este enfoque es pues, según el mismo autor, "asegurar que las políticas públicas se constituyan en una herramienta para la realización de los derechos humanos de las personas para las que se diseñan e implementan" (Pérez, 2007), con lo cual los derechos actúan simultáneamente como límites y como objetivos.

El enfoque de derechos humanos supone los siguientes pasos:

(i) Definir el contenido del derecho y las obligaciones del Estado;

(ii) Definir el problema que se intenta resolver, mediante la identificación de las barreras que enfrentan las personas para la satisfacción de sus derechos;

la acción e intervención de las autoridades públicas, a través de los diferentes planes y programas de desarrollo económico y social. 
(iii) Definir las estrategias de política, conforme con el contenido de los derechos y las obligaciones del Estado;

(iv) Implementar las acciones de manera coherente con los deberes de respeto y protección de los derechos humanos; y

(v) evaluar los resultados de la política y su impacto, tomando como referente su aporte para la protección y garantía de los derechos. (Pérez, 2007)

La Corte Constitucional incluye estas exigencias a la hora de verificar la constitucionalidad de las políticas públicas y adicionalmente incluye la necesidad de precisar: i) cronogramas de implementación (teniendo en cuenta el papel del indicador tiempo); ii) mecanismos e instrumentos específicos de coordinación interinstitucional incluido el ámbito territorial; iii) mecanismos de divulgación periódica de información para la población beneficiaria; iv) competencias y responsabilidades; v) mecanismos de corrección, vi) cobertura necesaria y suficiente.

Si bien los autores reseñados en la segunda parte de este texto han coincidido en señalar como contribución principal de la intervención de la Corte a través de sus fallos estructurales y en especial de la Sentencia T-025 de 2004, la inclusión del enfoque de derechos. Tal como se ha reseñado dicho enfoque parece insuficiente para caracterizar y explicar los indicadores de constitucionalidad de las políticas públicas desarrollados por la Corte.

Los autores y la Corte coinciden en que las políticas públicas orientadas a garantizar un derecho constitucional se justifican en la existencia de unas obligaciones específicas del Estado de garantizar y proteger los derechos sociales. Bajo esta consideración el enfoque de análisis de la política pública es un enfoque de derechos, que concibe como finalidad de la acción pública la garantía y protección de derechos de un sujeto particular.

Este enfoque, se complementa además, con el enfoque de gestión, el cual se entiende como el proceso de toma de decisiones dentro de una organización (planificación, 
organización, recursos, resultados, distribución de funciones) para alcanzar un objetivo. Este enfoque implica precisar que se quiere hacer y cuál es la mejor manera de lograrlo. Es un juicio de idoneidad de medios a fines. En resumen, como bien plantea el mismo Guendel (2005), se trata de armonizar el enfoque de los derechos con la institucionalidad.

Como se vio en los criterios de constitucionalidad desarrollados por la Corte, su orientación ha sido hacia los resultados y hacia la verificación de la idoneidad de las acciones dispuestas por el estado para lograr esos resultados, así se precisaron unos requisitos mínimos que debe contener la decisión acerca de los medios adecuados para alcanzar el goce efectivo de derechos, y en este sentido, el deber de planificar y precisar los actores involucrados, las funciones de cada uno, la forma en que se contribuye al goce efectivo de derechos y la medición de resultados.

Ya Cesar Rodríguez y Diana Rodríguez, habían destacado como efecto de política pública de la sentencia T-025 de 2004, el diálogo conceptual entre las políticas públicas y los derechos humanos, hallando su máxima expresión en los indicadores de goce efectivo de derechos "Un hibrido jurídico-económico". No obstante como se ha expuesto la intervención de la Corte a través de la fijación de los mínimos de racionalidad de las políticas públicas no se concentró sólo en la medición de los resultados de las mismas, sino que estableció una serie de cuestiones que deben ser precisadas en el diseño de las políticas públicas que permiten determinar si los medios escogidos son idóneos para el logro de la realización de los derechos de que se trate, si hay un marco de implementación real y ajustado.

Si bien se puede decir que el enfoque de gestión (planeación, precisión de metas a corto, mediano y largo plazo, medición de resultados) ya existía en las directrices que desde el Departamento Nacional de Planeación se establecen para la formulación de proyectos de inversión, no se habían aplicado estos mismos parámetros en el diseño de políticas y programas con objetivos más amplios como el goce efectivo de derechos y no se habían establecido como indicadores de constitucionalidad de las políticas públicas sociales. 


\section{Conclusiones}

Este texto tuvo por objeto analizar la jurisprudencia de la Corte Constitucional y determinar se a partir de la misma se ha modificado en Colombia el enfoque de las políticas públicas. Como se vio en el análisis desarrollado, en la jurisprudencia de la Corte Constitucional se evidencia una clara preocupación por la materialidad de los derechos reconocidos en la constitución, la Corte ha enfatizado su actividad de judicialización de las políticas públicas en la verificación de la capacidad de las mismas para producir resultados concretos de satisfacción de derechos.

Esta preocupación se ve reflejada en la línea jurisprudencial consolidada acerca de la constitucionalidad de las políticas públicas orientadas a garantizar un derecho constitucional. A partir de esta línea jurisprudencial se han precisado unos requisitos que deben satisfacer las políticas públicas para ser constitucionales, estos requisitos operan como indicadores de constitucionalidad de las políticas públicas, de cuyo análisis y verificación se concluye la adecuación de una política pública pública a los mandatos constitucionales.

Esta línea jurisprudencial incluye la definición de tres condiciones de constitucionalidad de las políticas públicas, de cuyo análisis la Corte Constitucional ha derivado consecuencias concretas respecto de la declaración de exequibilidad de una norma o practica gubernamental y ha respaldado i) la exigencia del diseño de políticas públicas; ii) la exigencia de elaboración de planes concretos; iii) la exigencia de progresividad; y iv) la inclusión de la participación en todo el ciclo de la política pública. Ahora bien, ¿existe un nuevo enfoque teórico de análisis de las políticas públicas?

Los estudios reseñados en el segundo apartado de este texto se concentraron en justificar la intervención de la Corte en la política pública a través de los fallos estructurales, a partir de la identificación de los efectos positivos de la misma, tales como i) la visibilización de problemas de respeto y garantía de los derechos humanos; ii) la democratización del ciclo de la política pública mediante la participación; y iii) el fortalecimiento de los procesos de evaluación de las políticas públicas. 
Los autores coincidieron en señalar como efecto principal de la intervención de la Corte la inclusión del enfoque de derechos en las políticas públicas, no obstante este enfoque no es suficiente para explicar los indicadores de constitucionalidad elaborados por la Corte pues dejan de lado el análisis de la idoneidad de los medios definidos por el órgano ejecutor de la política pública y de los ámbitos de implementación en los que ha hecho énfasis la jurisprudencia y de los que ha derivado ordenes concretas

La Corte Constitucional ha evidenciado que los obstáculos para la garantía de los derechos humanos reconocidos por la Constitución están en la propia institucionalidad, en el proceso de diseño, implementación y evaluación de la política pública, que se queda en el ámbito declarativo de objetivos y que no se traduce acciones concretas y planes operativos de implementación.

Con el enfoque de gestión de derechos y la precisión de los indicadores de constitucionalidad de las políticas públicas se impactan positivamente el proceso de democratización del Estado Colombia y se avanza en el logro de los fines que como sociedad organizada hemos definido en nuestra Constitución Política, entre ellos la vigencia de los derechos humanos y la existencia de un orden social justo, dado que se constituye en una herramienta que contribuye a la materialización de los derechos constitucionales. Así las cosas, la judicialización de la política pública no sólo es admisible sino también deseable. 


\section{REFERENCIAS}

Basch, F. (2010). Breve introducción al litigio de reforma estructural. Remedio judiciales y monitoreo de ejecución de Sentencia en el Litigio de Reforma Estructural. Buenos Aires.

Bugallo, J. M. (2013). El litigio de reforma estructural. Necesidad de una regulación normativa. Revista de derecho procesal Civil y Comercial (IJ-LXVIII-578).

Bullard G., A. (S.D.). S.F Ezquizofrenia Jurídica. El impacto del análisis económico del derecho en el Perú. Revista Themis (44), 17-35. Recuperado de http://dike.pucp.edu.pe/ doctrina/civ_art56.PDF

Cepeda, M. (2004). Las sentencias de la corte con implicaciones económicas: reflexiones con ánimo constructivo. XXVIII Jornadas Colombianas de Derecho Tributario. Cartagena de Indias ICDT.

Colombia, Corte Constitucional. (2004, octubre) Sentencia T - 025

Colombia, Corte Constitucional (2002). Sentencia T 595 de 2012

Couso, J. (2004). Consolidación democrática y poder judicial: los riesgos de la judicialización de la política. Revista de Ciencia Política, 24(2), 29-48.

Departamento Nacional de Planeacion DNP. (2009). Guia Metodológica para la formulación de indicadores. Bogotá.

Garcia Jaramillo, L. (2011). Aproximación a la discusión sobre políticas públicas y justicia constitucional: a propósito del estado de cosas inconstitucional. Estudios de Derecho, 68(152), 79-112.

Gómez Ramírez, M. (2010). El Estado de cosas Inconstitucional. Análisis de los motivos de la Corte para declararlo. Medellín: Universidad Pontificia Bolivariana. Recuperado de http://repository.upb.edu.co:8080/jspui/bitstream/123456789/83/1/TRABAJO\%20 DE\%20GRADO.pdf 
Güendel, L. (2000). "la política pública y la ciudadanía desde el enfoque de los Derechos Humanos: La búsqueda de una nueva utopía”. En S. E. Reuben Soto, Política Social. Vinculo entre el Estado y la Sociedad. Costa Rica: Universidad de Costa Rica. Recuperado de http://www.civilisac.org/web/wp-content/uploads/derechos-humanos-y-polc3adticas-pc3bablicas-guendel.pdf

Herrero, A. (2011). La incidencia de la Corte Suprema de Justicia en la formulación de políticas públicas: una exploración empírica del caso argentino. Revista política, 49(1), 71-106.

Jinesta Lobo, E. (1997). El control jurisdiccional de la adminsitración pública. Revista Judi$\operatorname{cial}(63), 98-112$.

Linares, S. (2008). La (I) Legitimidad Democrática del control judicial de las leyes. Madrid: Marcial Pons.

López G. A. (2011). El Juez constitucional colombiano como legislador positivo: ¿Un Gobierno de los Jueces? Revista Mexicana de Derecho Constitucional(24), 169-193.

López D. E. (2006). El derecho de los jueces. Bogotá: Legis.

Olaiz-González, J., \& Bosco López, J. (2011). El rol del Juez en la adjudicación de los derechos individuales de incidencia colectiva: Una oportunidad para el litigio estructural en México. En S. Pereira Campos, Modernización de la justicia civil. (pp. 949-970). Montevideo: Universidad de Montevideo.

Pérez L. E. (2007). Desarrollo, derechos sociales y políticas públicas. En L. E. Pérez Murcia, R. Uprimny Yepes, \& C. Rodríguez Garavito, Los derechos sociales en serio: hacia un diálogo entre derechos y políticas públicas. (pp. 71-130). Bogotá: Dejusiticia.

Prieto L. (2007). Derechos fundamentales, neoconstitucionalismo y ponderación judicial. Lima: Palestra Editores. 
Quinche M., \& Rivera Rugeles, J. (2010). El control judicial de las políticas públicas como instrumento de inclusión de los derechos humanos. Vniversitas(121), 113-138.

Rodríguez C. (2014). Evaluando el impacto y promoviendo la implementación de las sentencias estrcuturales sobre DESC en Colombia. Recuperado de http://www.escr-net.org/usr_doc/ Rodriguez-Colombia-espa\%C3\%B1ol.pdf

Rodríguez C., \& Rodríguez Franco, D. (2010). Cortes y cambio social. Como la Corte Constitucional transformo el desplazamiento forzado en Colombia. Bogotá: Dejusticia.

Roth D, A. N. (2010). ¿Política, programa o proyecto? (D. N. Planeación, Ed.) Boletin Politica Publica Hoy(8).

Upimny R., \& Rodríguez Garavito, C. (2007). Contitución, modelo económico y políticvas públicas en Colombia: el caso de gratuida de la educación primaria. . En Los derechos sociales en serio: hacia un diálogo entre derechos y politicas públicas. (pp. 23-71). Bogotá: Dejusticia - IDEP.

Uprimny R. (2007). La judicialización de la política en Colombia: Casos, potencialidades y riesgos. $\operatorname{Sur}(6), 61$.

Valderrama C. A. (2010). Corte Constitucional colombiana: un actor relevante en el ciclo de las políticas. El caso de la política pública para la población desplazada por la violencia. México: Secretaria de Educación Publica de Médico y COLFUTURO. 